\title{
Rendimento de feijão-caupi cultivado com esterco bovino e adubo mineral.
}

\author{
Ademar P. Oliveira; Jucilene S. Araújo; Edna Ursulino Alves; Michelle A. S. Noronha; Christiane M. \\ Cassimiro; Flávia G. Mendonça \\ UFPB-CCA, C. Postal 02, 58.397-000 Areia-PB. E-mail: ademar@cca.ufpb.br
}

\section{RESUMO}

O feijão-caupi, conhecido no Nordeste Brasileiro por feijãomacassar ou feijão-de-corda é uma das principais culturas desta região, consumido sob a forma de grãos secos ou grãos verdes, tipo ervilha. Na Paraíba detém $75 \%$ das áreas de cultivo com feijão, sendo que o baixo rendimento é atribuído à falta de estudos sobre nutrição mineral. Este trabalho teve como objetivo avaliar o efeito de diferentes doses de esterco bovino, na presença ou ausência de adubo mineral, sobre o rendimento de vagens, de grãos verdes e secos do feijão-caupi, cultivar IPA 206. O experimento foi conduzido na Universidade Federal da Paraíba, em Areia, de setembro/1998 a janeiro/1999, em delineamento experimental de blocos casualizados, com os tratamentos distribuídos em esquema fatorial $5 \times 2$, onde o primeiro fator correspondeu às doses de esterco bovino $(0,10,20$, 30 e 40 t/ha) e, o segundo fator à presença e ausência de adubo mineral, em quatro repetições. $\mathrm{O}$ rendimento máximo estimado de vagens $(9,64 \mathrm{t} / \mathrm{ha})$ foi obtido com $25 \mathrm{t} / \mathrm{ha}$ de esterco bovino na presença do adubo mineral, enquanto que na ausência de adubo mineral o rendimento de vagens aumentou com a elevação das doses de esterco bovino, na ordem de $49,3 \mathrm{~kg} / \mathrm{ha}$ para cada tonelada de esterco bovino adicionado ao solo. $\mathrm{O}$ rendimento de grãos verdes na presença de adubo mineral atingiu valor máximo estimado (6,8 t/ha) na dose ótima estimada de 17 t/ha de esterco bovino. Na ausência de adubo mineral, o rendimento de grãos verdes, aumentou com a elevação das doses de esterco bovino, na ordem de $47,9 \mathrm{~kg} / \mathrm{ha}$ para cada tonelada de esterco bovino adicionado ao solo. $\mathrm{O}$ rendimento de grãos secos na presença de adubo mineral atingiu valor máximo estimado (3,03 t/ha) na dose de $21 \mathrm{t} / \mathrm{ha}$ de esterco bovino, enquanto na ausência de adubo mineral a dose de $25 \mathrm{t} / \mathrm{ha}$ de esterco bovino foi responsável pelo rendimento máximo de grãos secos $(2,00$ t/ha).

Palavras-chave: Vigna unguiculata, adubação organo-mineral, vagens, grãos verdes, grãos secos, produção.

\begin{abstract}
Yield of cowpea-beans cultivated with bovine manure and mineral fertilization.

The cowpea-bean, known in the Brazilian Northeast as 'macassar-bean' or rope bean is one of the main crops of this region being consumed as dry beans or green beans (pods and/or immature grain). In Paraíba, it is cultivated in almost all regions, representing $75 \%$ of the area cultivated with common dry beans. The low yield is due to the lack of a program of mineral nutrition. This experiment was carried out to evaluate the effect of different levels of bovine manure in the presence or absence of mineral fertilizer on pods and green and dry grains yield of the cowpea-bean, cv. IPA 206. The experiment was performed in the Federal University of Paraíba, in Brazil, from September/1998 to January/1999, in a randomized blocks design, where the treatments were distributed in a factorial scheme $5 \times 2$, with the first factor corresponding to levels of bovine manure $(0,10,20,30$ and $40 \mathrm{t} / \mathrm{ha})$ and, the second factor, the presence or absence of mineral fertilizer, in four replications. Each plot consisted of 20 plants, spaced $0.80 \times 0.40 \mathrm{~m}$ apart. The estimated maximum yield of pods $(9.64 \mathrm{t} / \mathrm{ha})$ was obtained with $25 \mathrm{t} / \mathrm{ha}$ of bovine manure in the presence of mineral fertilizer, while in the absence of mineral fertilizer, the yield of pods, increased with the increasing levels of bovine manure, in the order of $49.3 \mathrm{~kg} / \mathrm{ha}$ to each ton of bovine manure added to the soil. The yield of green grains in the presence of mineral fertilizer reached estimated maximum value $(6.8 \mathrm{t} / \mathrm{ha})$ in the estimated optimum level of $17 \mathrm{t} / \mathrm{ha}$ of bovine manure. In the absence of mineral fertilizer, the yield of green grains, increased with the increasing of the levels of bovine manure in the order of $47.9 \mathrm{~kg} / \mathrm{ha}$ to each ton of bovine manure added to soil. The yield of dry grains in the presence of mineral fertilizer reached estimated maximum value $(3.03 \mathrm{t} / \mathrm{ha})$ in the level of $21 \mathrm{t} / \mathrm{ha}$ of bovine manure. In the absence of mineral fertilizer, the level of $25 \mathrm{t} / \mathrm{ha}$ of bovine manure was responsible for the maximum yield of dry grains (2.00 t/ha).
\end{abstract}

Keywords: Vigna unguiculata Walp., organic-mineral fertilization, pods, green grains, dry grains, yield.

(Aceito para publicação em 24 de janeiro de 2001)

$\mathrm{O}$ feijão-caupi (Vigna unguiculata (L.) Walp), conhecido por feijãomacassar ou feijão-de- corda é uma fonte de renda alternativa e considerado alimento básico da população da Região Nordeste do Brasil. O consumo do mesmo pode ser na forma de grãos maduros e de grãos verdes, ("feijão-verde" com teor de umidade entre $60 \mathrm{e} 70 \%$ ). É bastante apreciado por seu sabor e cozimento mais fácil, sendo utilizado como "feijão-verde", em pratos típicos da região Nordestina (Ferreira \& Silva, 1987; Oliveira \& Carvalho, 1988; Silva \& Oliveira, 1993). No Estado da Paraíba, é cultivado em quase todas micro-regiões, onde detém $75 \%$ das áreas de cultivo com feijão (IBGE,1996).

Em algumas regiões do Estado da Paraíba níveis baixos de produtividade têm sido constatados. Sabe-se que um dos problemas associados com a baixa produtividade é o plantio de cultivares tradicionais com pouca capacidade produtiva e a falta de um programa de nutrição mineral para a cultura.

O feijão-caupi pode ser cultivado em solos com regular teor de matéria orgânica e razoável fertilidade. Em solos de baixa fertilidade, necessita de aplicações de fertilizantes mineral e/ou orgânico. Contudo, o excesso de matéria orgânica pode ocasionar um desenvolvimento 


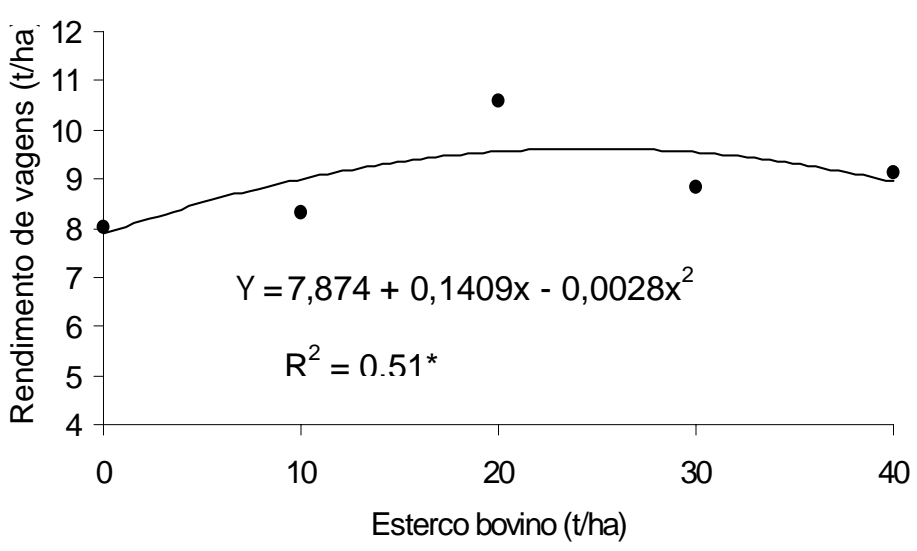

Figura 1. Rendimento de vagens de feijão-caupi, cultivar IPA 206, em função de doses de esterco bovino na presença de adubo mineral. Areia, UFPB, 1999.

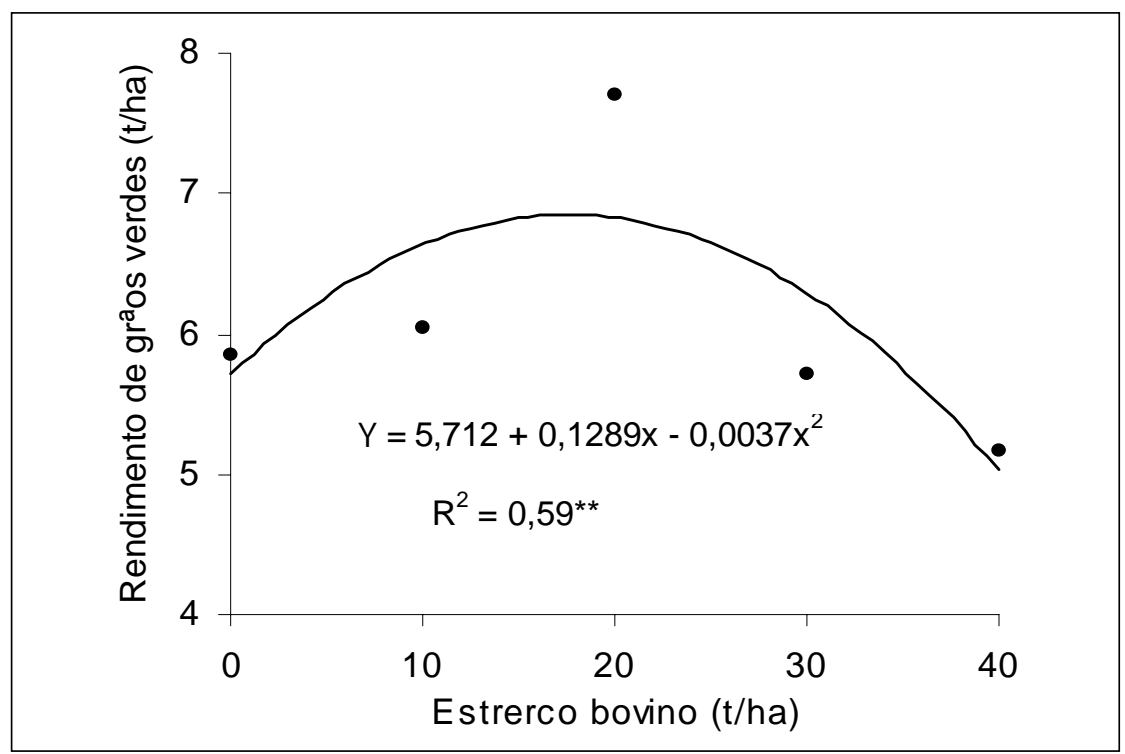

Figura 2. Rendimento de grãos verdes de feijão-caupi, cultivar IPA 206, em função de doses de esterco bovino na presença de adubo mineral. Areia, UFPB, 1999.

vegetativo acentuado em detrimento da produção de vagens (Oliveira, 1982).

Embora o esterco bovino seja um dos resíduos orgânicos com maior potencial de uso como fertilizante, principalmente em pequenos estabelecimentos agrícolas na região Nordestina, pouco se conhece a respeito das quantidades a serem utilizar no feijão-caupi, que permitam a obtenção de rendimentos satisfatórios.

Em relação à adubação mineral, a necessidade da aplicação de nitrogênio, não deve ser considerada como fator crítico de produção no feijão-caupi. Em áreas recém-trabalhadas, pode ser usada uma adubação nitrogenada em torno de $20 \mathrm{~kg} / \mathrm{ha}$ de $\mathrm{N}$. O fósforo é elemento importante para a cultura no processo de formação de grãos. As recomendações de seu fornecimento à cultura, encontram-se na faixa de 50 a $100 \mathrm{~kg} / \mathrm{ha}$ de $\mathrm{P}_{2} \mathrm{O}_{5}$. O potássio, como para a maioria das plantas cultivadas, não tem apresentado resultado constante e positivo no feijão-caupi. Seu emprego, entretanto, tem sido recomendado baseado no balanceamento das fórmula de adubação. O feijão-caupi pode responder até a $60 \mathrm{~kg} / \mathrm{ha}$ de $\mathrm{K}_{2} 0$, mas as recomendações nunca devem ultrapassar a $30 \mathrm{~kg}$ / ha (Oliveira, 1982).

O presente trabalho foi desenvolvido visando avaliar o emprego do esterco bovino na presença e ausência de adubo mineral, sobre o rendimento de feijão-caupi.

\section{MATERIAL E MÉTODOS}

Foi instalado um experimento na Universidade Federal da Paraíba (UFPB), em Areia, no período de setembro de 1998 a janeiro de 1999, em Latossolo Vermelho-Amarelo, onde foram estabelecidos dez tratamentos, constituídos de cinco doses de esterco bovino na presença ou ausência de adubo mineral, distribuídos em esquema fatorial $5 \times 2$ em blocos casualizados com quatro repetições. A análise do solo indicou a seguinte composição: $\mathrm{pH}=$ 6,$3 ; \mathrm{P}=93,0 \mathrm{mg} / \mathrm{dm}^{3} ; \mathrm{K}=165,0 \mathrm{mg} /$ $\mathrm{dm}^{3} ; \mathrm{Al}^{+3}=0,0 \mathrm{cmol} / \mathrm{dm}^{3} ; \mathrm{Ca}^{+2}=2,80$ $\mathrm{cmol} / \mathrm{dm}^{3} ; \mathrm{Mg}^{+2}=1,20 \mathrm{cmol} / \mathrm{dm}^{3}$ e matéria orgânica $=10,40 \mathrm{~g} / \mathrm{dm}^{3}$. O esterco bovino apresentava as seguintes características; $\mathrm{P}=3,6 \mathrm{~g} / \mathrm{kg} ; \mathrm{K}=4,1 \mathrm{~g} / \mathrm{kg} ; \mathrm{N}$ $=3,8 \mathrm{~g} / \mathrm{kg}$; matéria orgânica $=182,07$ $\mathrm{g} / \mathrm{dm}^{3}$ e relação $\mathrm{C} / \mathrm{N}=10 / 1$. As doses de esterco bovino empregadas $(0,10,20$, 30 e $40 \mathrm{t} / \mathrm{ha}$ ) foram aplicadas juntamente com o adubo mineral sete dias antes da semeadura. A adubação mineral seguiu recomendações do Laboratório de Química e Fertilidade de Solo da UFPB e consistiu da aplicação de $500 \mathrm{~kg} / \mathrm{ha}$ de superfosfato simples, $68 \mathrm{~kg} / \mathrm{ha}$ de cloreto de potássio e $500 \mathrm{~kg} / \mathrm{ha}$ de sulfato de amônio, aplicado em cobertura aos 30 dias após a semeadura.

O preparo do solo constou de aração, gradagem e abertura de covas de plantio. As parcelas foram compostas de 20 plantas da cultivar IPA-206, espaçadas de $0,80 \mathrm{~m}$ entre fileiras e $0,40 \mathrm{~m}$ entre plantas, sendo dez plantas empregadas para avaliar o rendimento de vagens e de grãos verdes e outras dez para avaliar o rendimento de grãos secos. Durante a condução da cultura foram realizadas pulverizações à base de Deltametrina 2,5E, a cada quinze dias após a emergência, visando o controle da cigarrinha verde (Empoasca braemer). No período de ausência de chuvas foi realizada irrigação por aspersão. Efetuou-se também capinas com auxílio de enxadas, procurando-se manter a cultura livre de plantas invasoras. As colheitas, em número de cinco, foram realizadas à medida que a vagem iniciava sua maturação para obtenção do rendimento de vagens e de grãos verdes e quando secava para obtenção de grãos secos. 
Os resultados obtidos foram interpretados por meio das análises de variância e de regressão. Quando possível, os modelos de regressão linear e quadrática foram utilizados para estimar as respostas das características avaliadas. Nas significâncias das análises de variância e de regressão foram considerados os níveis de probabilidade de $5 \%$ e $1 \%$ pelo teste F. O teste " $t$ " foi utilizado para testar os coeficientes da regressão nos níveis de probabilidade de $5 \%$ e $1 \%$.

\section{RESULTADOS E DISCUSSÃO}

O rendimento de vagens, de grãos verdes e de grãos secos no feijão-caupi, foram influenciados $(\mathrm{P} \angle 0,05)$ pelos tratamentos.

Os rendimentos máximos estimados de vagens $(9,64 \mathrm{t} / \mathrm{ha})$ e de grãos ver$\operatorname{des}(6,8 \mathrm{t} / \mathrm{ha})$, calculados pela derivação das equações descritas nas figuras $1 \mathrm{e}$ 2, foram obtidos com 25 e 17 t/ha de esterco bovino, respectivamente, ambos na presença do adubo mineral. $\mathrm{Na}$ ausência de adubo mineral o rendimento de vagens e de grãos verdes aumentou com a elevação das doses de esterco bovino na ordem de 49,3 kg/ha de vagem e de $47,9 \mathrm{~kg} / \mathrm{ha}$ de grãos verdes a cada tonelada de esterco adicionada ao solo (Figura 3).

A partir das derivadas das equações de regressão (Figura 4), o rendimento de grãos secos na presença de adubo mineral, atingiu valor máximo estimado $(3,03 \mathrm{t} / \mathrm{ha})$ na dose de $21 \mathrm{t} / \mathrm{ha}$ de esterco bovino. Na ausência de adubo mineral a dose de $25 \mathrm{t} / \mathrm{ha}$ de esterco bovino foi responsável pelo rendimento máximo de grãos $\operatorname{secos}(2,00$ t/ha).

Os rendimentos máximos estimados de vagens $(9,64 \mathrm{t} / \mathrm{ha})$, de grãos verdes (6,8 t/ha) e de grãos $\operatorname{secos}(3,03 \mathrm{t} / \mathrm{ha})$ obtidos pelo uso do esterco, na presença do adubo mineral e de grãos secos na sua ausência (2,00 t/ha), evidenciam uma boa produtividade do feijão-caupi, cultivar cultivar IPA 206 na micro-região de Areia- PB, superando os resultados obtidos por Silva et al. (1993), Silva \& Oliveira (1993) e Silva \& Freitas (1996) em cultivos convencionais. Provavelmente, durante o crescimento e desenvolvimento das plantas, as doses de esterco bovino, juntamente com os

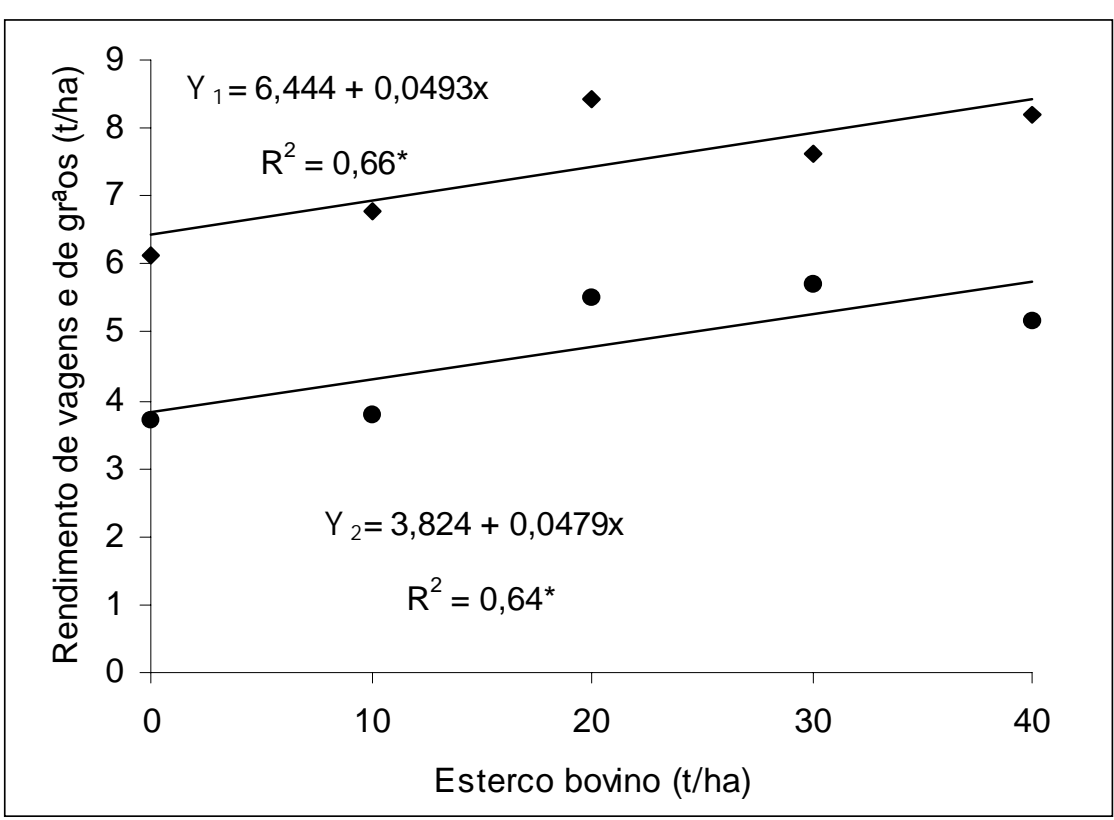

Figura 3. Rendimento de vagens $\left(\mathrm{Y}_{1}\right)$ e de grãos verdes $\left(\mathrm{Y}_{2}\right)$ no feijão-caupi, cultivar IPA 206, em função de doses de esterco bovino na ausência de adubo mineral. Areia, UFPB, 1999.

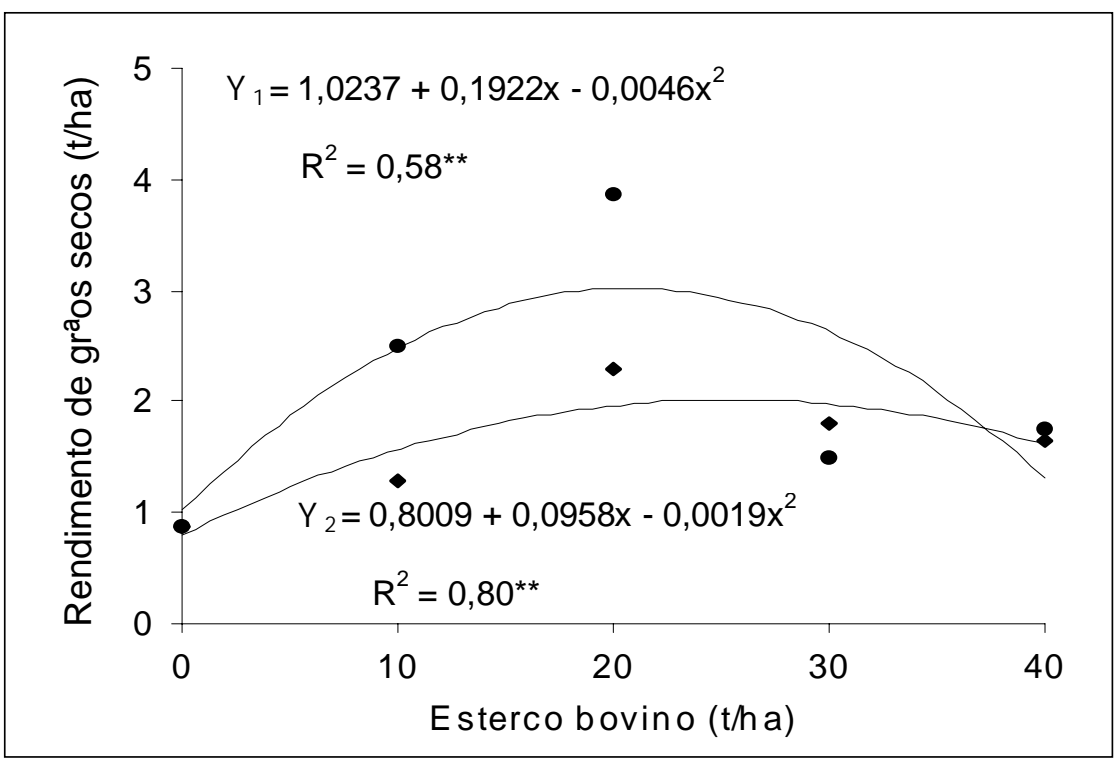

Figura 4. Rendimento de grãos secos de feijão-caupi, cultivar IPA 206, em função de doses de esterco bovino na presença $\left(\mathrm{Y}_{1}\right)$ e ausência $\left(\mathrm{Y}_{2}\right)$ de adubo mineral. Areia, UFPB, 1999.

nutrientes minerais adicionados ao solo, supriram de forma equilibrada as necessidades nutricionais da cultura. A aplicação adequada de esterco de boa qualidade pode suprir as necessidades das plantas em macronutrientes, devido a elevação nos teores de $\mathrm{P}$ e $\mathrm{K}$ disponível (Machado et al., 1983). Maiores produções de grãos em feijão-comum, com doses de adubos orgânicos foram relatados (Vieira, 1988; Galbiatti et al., 1996; Henriques, 1997).
A estabilização e queda no rendimento de vagens e de grãos verdes e secos nas doses mais elevadas de esterco bovino na presença de adubo mineral, podem ser devidas ao excesso de nutrientes fornecidos à cultura (Malavolta, 1989; Huett, 1989; Smith \& Hadley, 1989). Resultados de vários estudos têm mostrado que o nitrogênio e o potássio, são os elementos que o feijoeiro retira do solo em maiores quantidades. Fósforo, cálcio, magnésio e 
enxofre são também extraídos em quantidades consideráveis (Guedes \& Junqueira Neto, 1978).

Uma vez que o experimento foi instalado em solo com teores elevados de $\mathrm{P}$ e $\mathrm{K}$, acredita-se que os benefícios do esterco bovino sobre o rendimento do feijão-caupi, na presença e ausência de adubo mineral, devam-se não somente ao suprimento de nutrientes, mas também a melhoria de outros constituintes da fertilidade do solo, no fornecimento de água, no arranjamento da sua estrutura por meio de formação de complexos húmus-argilosos e consequente aumento na CTC, (Marchesini et al., 1988; Yamada \& Kamata, 1989), proporcionando melhor aproveitamento dos nutrientes originalmente presentes. Essas condições provavelmente permitiram ao feijão-caupi o seu potencial de produção de vagens e grãos verdes e secos, induzida pela sua constituição genética.

\section{AGRADECIMENTOS}

Os autores agradecem à professora Sheila Costa de Farias pela correção do Abstract e aos agentes em Agropecuária Francisco de Castro Azevedo, José Barbosa de Souza, Francisco Soares de Brito, Francisco Silva do Nascimento e Expedito de Souza Lima que viabilizaram a execução dos trabalhos de campo.

\section{LITERATURA CITADA}

FERREIRA, J.M.; SILVA, P.S.L. Produtividade de "Feijão verde" e outras características de cultivares de caupí. Pesquisa Agropecuária Brasileira, Brasília, v. 22, n. 1, p. 55-58, 1987.

GALBIATTI, J.A.; GARCIA, A.; SILVA, M.L.; MASTROCOLA, M.A.; CALDEIRA, D.S.A. Efeitos de diferentes doses e épocas de aplicação de efluente de biodigestor e da adubação mineral em feijoeiro-comum (Phaseolus vulgaris L.) submetido a duas lâminas de água por meio de irrigação por sulco. Científica, São Paulo, v. 24, n. 1, p. 63-74, 1996.

GUEDES, G.A.A.; JUNQUEIRA NETO, A Calagem e adubação. Informe Agropecuário, Belo Horizonte, v. 4, n. 46, p. 21-23, 1978.

HENRIQUES, R.C. Análise da fixação de nitrogênio por bactérias do gênero Rhizobium em diferentes concentrações de fósforo e de matéria orgânica na cultura do feijão (Phaseolus vulgaris ) em Regossolo. Areia: UFPB, 1997, 37 p. (Graduação em Agronomia).

HUETT, D.O. Effect of nitrogen on the yield and quality of vegetables. Acta Horticulturae. v. 247, p. 205 -209, 1989.

IBGE. Instituto Brasileiro de Geografia e Estatística. Anuário estatístico. Rio de Janeiro, 1996.

MACHADO, M.O.; GOMES, A.S.; TURATTI, E.A.P.; SILVEIRA JUNIOR, P. Efeito da adubação orgânica e mineral na produção do arroz irrigado e nas propriedades químicas e físicas do solo de Pelotas. Pesquisa Agropecuária Brasileira, Brasília, v. 18, n. 6, p. 583-591, 1983.

MALAVOLTA, E. ABC da adubação. 5. ed. São Paulo: Agronômica Ceres, 1989. 292 p.

MARCHESINI, A.; ALLIEVI, L.; COMOTTI, E.; FERRARI, A. Long-term effects of quality compost treatment on soil. Plant and Soil, v.106, p. 253-261, 1988.
OLIVEIRA, A.P. Noções de solo e nutrição de caupi. In: I CURSO DE PRODUÇÃO DE CAUPI. 1982. EMBRAPA/CNPFA. 35 p.

OLIVEIRA, A.P.; CARVALHO, A.M.. A cultura do caupi nas condições de clima e de solo dos trópicos úmidos de semi-árido do Brasil. In: ARAÚJO, J.P.P.; WATT, E.E. O caupi no Brasil, Brasília, EMBRAPA-CNPAF, p. 65-69, 1988.

SILVA, P.S.L.; FREITAS, C.J.. Rendimento de grãos verdes de milho e caupí em cultivos puros e consorciadas. Revista Ceres, Viçosa, v. 43, n. 245, p. 28-38, 1996.

SILVA, P.S.L.; MONTENEGRO, E.E.; OLIVEIRA, F. Efeito da remoção de flores e vagens sobre as características do caupi (Vigna uguiculata (L) Walp). Revista Ceres, Viçosa, v. 40, n. 231, p. 502-512, 1993.

SILVA, P.S.L.; OLIVEIRA, C.N. Rendimentos de feijão verde e maduro de cultivares de caupi. Horticultura Brasileira, Brasília, v. 11, n. 2, p. 133-135, 1993.

SMITH, S.R.; HADLEY, P.A. Comparison of organic and inorganic nitrogen fertilizers their nitrate- $\mathrm{N}$ and ammonium-N release characteristics and effects on the growth response of lettuce (Lactuca sativa L. cv. Fortune). Plant and Soil, v. 115, n. 1, p. 135144, 1989.

VIEIRA, L.C. Efeitos do composto orgânico sobre o consórcio do feijão com o milho. Viçosa: UFV, 1988, 67 p. (Dissertação mestrado).

YAMADA, H., KAMATA, H. Agricultural technological evaluation of organic farming and gardening I. Effects of organic farming on yields of vegetables and soil physical and chemical properties. Bulletim of the Agricultural Research Institute of Kanagawa Prefecture, v. 130, p. 1-13. In: Horticultural. Abstract, v. 59, n. 10, p. 938-939, 1989. 